\title{
A sequential dynamic choice model to simulate demand in evacuation conditions
}

\author{
F. Russo \& G. Chilà \\ Mediterranea University of Reggio Calabria, Italy
}

\begin{abstract}
When a dangerous event occurs, a variety of events affects the system characteristics of users and of the transportation network in the time. Dynamic models allow us to simulate variation in choice probability from one time to another, considering temporal evolution of user characteristics and of dangerous event. Among dynamic models, sequential dynamic discrete choice models represent a special class and are proposed in this work to simulate evacuation conditions. Sequential tests are introduced to validate the proposed model and in order to ascertain whether current decisions are directly influenced by the most recent previous decisions. Sequential tests are specified for evacuation condition simulation and allow us to assess the significance of the reduction in uncertainty. Keywords: evacuation conditions, sequential dynamic demand model, sequential test.
\end{abstract}

\section{Introduction}

A discrete choice model could be specified, calibrated and implemented to simulate several choices of transport and mobility, such as transport mode, path choice and car ownership. Discrete choice models are defined in respect of several elements: decision maker, choice set, attributes and parameters, random residuals [1-3]. These elements vary if ordinary or evacuation conditions are considered $[4,5]$ and, for evacuation conditions, in relation to the event type which may lead a state of emergency [4-6].

The event type can be classified in relation to [4-6]: a natural or anthropogenic kind; immediate or delayed effect in the time; punctiform or diffuse effect in the space; involved component of transport system. 
Considering the effect in the time, demand models can be specified for a dangerous event with immediate or delayed effects, in relation to the time gap available between the time at which the dangerous event will happen is known and the time when the event starts its effects on the population [4, 7, 8]. For example, an event with delayed effect in the time is the hurricane. In this case the time gap above mentioned is different from zero and it's possible to identify several time intervals, such as:

- the interval between the time at which an hypothetical public decision maker decide to plan an evacuation from a considered area $\left(\mathrm{t}_{0}\right)$ and the time at which it's possible to know when the hurricane will be in the considered area $\left(\mathrm{t}_{1}\right)$;

- the interval between $t_{1}$ and the time at which the hurricane reach the considered area $\left(t_{2}\right)$;

- the interval between $t_{2}$ and the time at which the hurricane starts its effects $\left(\mathrm{t}_{3}\right)$;

- the interval between $t_{3}$ and the time at which the hurricane ceases its effects on the population $\left(\mathrm{t}_{4}\right)$.

For a formal definition of times $t_{i}, i=1,2,3,4$, we refer to Russo and Chilà $[4,5]$.

Usually, demand evacuation for dangerous event with delayed effect in the time is simulated in the literature considering a multi-step approach, including several user decisions: evacuate or not (generation), when (departure-time), towards which destination (distribution), by which transport mode (modal choice) and by which path (path choice).

In the literature two user decisions are simulated: evacuate or not and when. Generally, these decisions are simulated considering a statistical approach, using simple relationships such as means, rates and distributions [9, 10], which we could classify as static approach. However, in emergency conditions, when a variety of events affects the system characteristics of users and of the transportation network, the use of dynamic models is suggested.

Dynamic models give the choice probability while considering system evolution and allow us to simulate variation in choice probability from one time to another time. They could be specified as regards attributes $(X)$, parameters $(\beta)$ or random residuals $(\varepsilon)$ and are suggested in order to simulate also the situations in which new alternatives arise or previous ones are modified in their attributes, such as: path choice for high frequency services [11]; day-to-day dynamic path choice behaviour, for a private transport network [12]; vehicle ownership, when socio-economic properties of families and technical characteristics of vehicles change in time [13-17].

Formally, under the assumption of random utility theory, we can define as a dynamic model the model that gives the probability that user $n$ chooses the generic alternative $\mathrm{j}^{\mathrm{t}}$ in $\mathrm{t}$, if $\beta^{\mathrm{t}-1} \neq \beta^{\mathrm{t}}$ and $/$ or $\mathrm{X}^{\mathrm{t}-1} \neq \mathrm{X}^{\mathrm{t}}$, as:

$$
\begin{gathered}
\mathrm{P}^{\mathrm{n}, \mathrm{t}}\left[\mathrm{j}^{\mathrm{t}}\right]=\operatorname{prob}\left(\mathrm{U}^{\mathrm{n}, \mathrm{t}}\left[\mathrm{j}^{\mathrm{t}}\right]>\mathrm{U}^{\mathrm{n}, \mathrm{t}}\left[\mathrm{i}^{\mathrm{t}}\right] \forall \mathrm{j}^{\mathrm{t}}, \mathrm{i}^{\mathrm{t}} \in \mathrm{C}, \mathrm{j}^{\mathrm{t}} \neq \mathrm{i}^{\mathrm{t}}\right) \\
\text { with } \mathrm{P}^{\mathrm{n}, \mathrm{t}}\left[\mathrm{j}^{\mathrm{t}}\right] \neq \mathrm{P}^{\mathrm{n}, \mathrm{t}-1}\left[\mathrm{j}^{\mathrm{t}-1}\right] \forall \mathrm{j}^{\mathrm{t}} \mathrm{j}^{\mathrm{t}-1} \in \mathrm{C}, \mathrm{j}^{\mathrm{t}} \neq \mathrm{j}^{\mathrm{t}-1} \\
\mathrm{P}^{\mathrm{n}, \mathrm{t}-1}\left[\mathrm{j}^{\mathrm{t}-1}\right]=\operatorname{prob}\left(\mathrm{U}^{\mathrm{n}, \mathrm{t}-1}\left[\mathrm{j}^{\mathrm{t}-1}\right]>\mathrm{U}^{\mathrm{n}, \mathrm{t}-1}\left[\mathrm{i}^{\mathrm{t}-1}\right] \forall \mathrm{j}^{\mathrm{t}-1}, \mathrm{i}^{\mathrm{t}-1} \in \mathrm{C}, \mathrm{j}^{\mathrm{t}-1} \neq \mathrm{i}^{\mathrm{t}-1}\right)
\end{gathered}
$$


where

- $\quad \mathrm{t}$ the generic current time interval;

- $\mathrm{t}-1$ the generic previous time interval;

- $\mathrm{n}$ the generic user class;

- $\mathrm{j}^{\mathrm{t}}$ the chosen alternative in time $\mathrm{t}$;

- $\mathrm{i}^{\mathrm{t}}$ the generic alternative in time $\mathrm{t}$;

- $\mathrm{j}^{\mathrm{t}-1}$ the chosen alternative in time $\mathrm{t}-1$;

- $\mathrm{i}^{\mathrm{t}-1}$ the generic alternative in time $\mathrm{t}-1$;

with $\mathrm{j}^{\mathrm{t}}, \mathrm{i}^{\mathrm{t}} \in \mathrm{C}^{\mathrm{t}} ; \mathrm{j}^{\mathrm{t}-1}, \mathrm{i}^{\mathrm{t}-1} \in \mathrm{C}^{\mathrm{t}-1}$ and supposing that $\mathrm{C}^{\mathrm{t}}=\mathrm{C}^{\mathrm{t}-1}=\mathrm{C}$.

In the literature, several specifications of dynamic models are proposed. Generally they are not characterized by a statistical structure which allows us to analyze a given dynamic phenomenon, defining dynamic properties such as lag, significance, homogeneity. In the literature which deals with data analysis, a structure which allows dynamic analysis of phenomenon to be carried out is represented by the sequential analysis.

In this work we propose a special class of dynamic discrete choice model, which will name as sequential dynamic discrete choice model, considering properties of dynamic discrete choice model and the statistical structure of sequential analysis. In the section 2 we specify a sequential dynamic discrete choice model to simulate evacuation conditions, in the section 3 we propose sequential tests to validate the proposed model and, finally, in the section 4 we suggest main conclusions.

\section{Sequential dynamic discrete choice model to simulate evacuation conditions}

Main objective of sequential analysis methodology is to evaluate hypothetical dependences among transition frequencies, which are defined from antecedent to consequent states. This methodology allows us to record observed data preserving sequential information and also how to analyze such data in a way that makes use of its sequential nature $[18,19]$.

In sequential analysis, data related to user behaviour are recorded and analyzed, preserving sequential information and considering a statistical approach. Sequential analysis requires that data must be collected in a systematic way. The analyst must set the recording unit, which can be an interval or an event. Depending on how data were recorded, the analyst can extract different representations from the same recorded data for different purposes. Synthetically, there are at least four representation forms, termed the Sequential Data Interchange Standard: event sequences, state sequences, timed-event sequences, interval sequences.

In the following we refer to interval sequences, which are designed to accommodate interval recording in a simple and straightforward way: alternatives are simply listed as they occur and interval boundaries are represented by commas. 
Data collected sequentially are summarized using a transition frequency matrix (table 1) and a second matrix so-called transition probability matrix (table 2), [18, 19].

Table 1: $\quad$ Transition frequency matrix.

\begin{tabular}{|c|c|c|c|c|}
\hline & $\mathrm{t}$ & $\mathrm{I}$ & $\mathrm{j}$ & \\
\hline $\mathrm{t}-1$ & $\mathrm{i}$ & $\phi_{\mathrm{ii}}$ & $\phi_{\mathrm{ij}}$ & $\phi_{\mathrm{i}+}$ \\
\hline & $\mathrm{j}$ & $\phi_{\mathrm{ji}}$ & $\phi_{\mathrm{jj}}$ & $\phi_{j+}$ \\
\hline & & $\phi_{+\mathrm{i}}$ & $\phi_{+\mathrm{j}}$ & \\
\hline
\end{tabular}

Table 2: $\quad$ Transition probability matrix (so-called in sequential analysis).

\begin{tabular}{|l|r|c|c|c|}
\hline & $\mathrm{t}$ & $\mathrm{I}$ & $\mathrm{j}$ & \\
\hline $\mathrm{t}-1$ & $\mathrm{i}$ & $\pi_{\mathrm{ii}}$ & $\pi_{\mathrm{ij}}$ & $\pi_{\mathrm{i}+}$ \\
\hline & $\mathrm{j}$ & $\pi_{\mathrm{ji}}$ & $\pi_{\mathrm{jj}}$ & $\pi_{\mathrm{j}+}$ \\
\hline & & $\pi_{+\mathrm{i}}$ & $\pi_{\mathrm{ij}}$ & \\
\hline
\end{tabular}

The transition frequency matrix is a square matrix which has the same number of rows and columns as events; its generic element represents the transition frequency from $\mathrm{i}$ to $\mathrm{j}$, generic events or states of the system. These frequencies can also be converted by dividing each element of transition frequency matrix by the row total (e.g. $\phi_{\mathrm{ii}}$ and $\phi_{\mathrm{ij}}$ by $\phi_{\mathrm{i}+}, \phi_{\mathrm{ji}}$ and $\phi_{\mathrm{jj}}$ by $\phi_{\mathrm{j}+}$, respectively). The results can be arranged in a matrix called in (sequential analysis) literature transition probability matrix, even if probabilities as currently (De Finetti) defined are not present. In order to highlight the difference between transition probability matrix above mentioned and proposed sequential transition probability we will use for the first the symbol $\pi$ and for the second the symbol $p$. The rows of transition probability matrix sum to one.

Transition matrices are able to represent the choice set for a set of users who have made the same given choice in the previous period. In our work, the data are arranged into a transition matrix and are represented as sequences or chains of alternatives (or behavioural states). For each row of the transition matrix a sequential dynamic discrete choice model could be proposed. For each model, the choice set in the present period is defined as function of the choice set in the previous period. Each model is defined for the set of user who took a given choice in the previous period; this given choice corresponds to a given row of transition matrix. Therefore, a relation between previous and present choices is introduced. For each row of transition matrix the proposed model gives the probability of a user choosing the generic alternative in the current period $t$, conditional upon the probability of the user choosing a given alternative in the 
previous period $\mathrm{t}-1$. The introduced probability is termed a transition probability and could be classified as a special kind of conditional probability [16, 20, 21].

In order to simulate introduced transition probability, a sequential dynamic discrete choice model is defined. This model is derived considering properties of discrete choice models, properties of sequential analysis and choice alternatives related to the previous periods. Sequential dynamic discrete choice model represents a special class of dynamic discrete choice model, giving the choice probability according to the current and previous system condition, thus considering system evolution and earlier decisions.

Formally, a sequential dynamic discrete choice model is a dynamic model that gives the probability of user $n$ choosing the generic alternative $j^{t}$ in $t, j^{t} \in C^{t}$, conditional upon the probability that user $\mathrm{n}$ has chosen the generic alternative $\mathrm{j}^{\mathrm{t}-1}$ in the previous period $\mathrm{t}-1, \mathrm{j}^{\mathrm{t}-1} \in \mathrm{C}^{\mathrm{t}-1}$, as in the following relation:

$$
\begin{aligned}
& \mathrm{P}^{\mathrm{n}, \mathrm{t}}\left[\mathrm{j}^{\mathrm{t}} / \mathrm{j}^{\mathrm{t}-1}\right]=\operatorname{prob}\left(\mathrm{U}^{\mathrm{n}, \mathrm{t}}\left[\mathrm{j}^{\mathrm{t}}\right]>\mathrm{U}^{\mathrm{n}, \mathrm{t}}\left[\mathrm{i}^{\mathrm{t}}\right] \forall \mathrm{j}^{\mathrm{t}}, \mathrm{i}^{\mathrm{t}} \in \mathrm{C}, \mathrm{j}^{\mathrm{t}} \neq \mathrm{i}^{\mathrm{t}}\right) / \\
& \operatorname{prob}\left(\mathrm{U}^{\mathrm{n}, \mathrm{t}-1}\left[\mathrm{j}^{\mathrm{t}-1}\right]>\mathrm{U}^{\mathrm{n}, \mathrm{t}-1}\left[\mathrm{i}^{\mathrm{t}-1}\right] \forall \mathrm{j}^{\mathrm{t}-1}, \mathrm{i}^{\mathrm{t}-1} \in \mathrm{C}, \mathrm{j}^{\mathrm{t}-1} \neq \mathrm{i}^{\mathrm{t}-1}\right)
\end{aligned}
$$

assuming that:

a physical alternative can change one or more attributes and/or parameters from $\mathrm{t}-1$ to $\mathrm{t}$, without modifying her intrinsic nature; in this way $\mathrm{j}^{\mathrm{t}}$ may or may not be equal to $\mathrm{j}^{\mathrm{t}-1}$, with $\mathrm{j}^{\mathrm{t}}, \mathrm{j}^{\mathrm{t}-1} \in \mathrm{C}^{\mathrm{t}}=\mathrm{C}^{\mathrm{t}-1} \equiv \mathrm{C}$;

$\mathrm{C}^{\mathrm{t}}$ is equal to $\mathrm{C}^{\mathrm{t}-1}$ if both have the same physical alternatives, even if one or more alternatives change one or more attributes or parameters from t- 1 to $t$.

The probability, in this way defined (see eq. 4), is termed a sequential transition probability and is a kind of conditional probability.

In the same way we can obtain the probability of user $n$ choosing the generic alternative $z^{t} \neq j^{t}, z^{t} \in C^{t}$, conditional upon the probability that user $n$ has chosen the generic alternative $\mathrm{j}^{\mathrm{t}-1}$ in the previous period $\mathrm{t}-1, \mathrm{z}^{\mathrm{t}-1} \in \mathrm{C}^{\mathrm{t}-1}$.

In this section we propose the general structure of a sequential dynamic discrete choice model simulating evacuation conditions.

We suppose that the decision maker is a generic household which could evacuate at each time period before the hypothetical dangerous event with delayed effects in a period of time $T=\left[\mathrm{t}_{1}, \mathrm{t}_{3}\right]$ (see the hurricane example, sec. 1 ). We subdivided the period $\mathrm{T}$ in sub-interval $\tau$, at which the generic household could choose evacuating. We suppose the absence of targets imposed by a decision maker and we define a choice set $\mathrm{C}$ including, at each $\tau$, the alternatives:

- $\quad$ evacuate in $\tau(\mathrm{e})$;

- $\quad$ non evacuate in $\tau$ (ne).

In this case the general transition frequency matrix (table 3) comes a transition frequency vector (table 4). In fact, even if the formal transition frequency matrix is with two rows (for behavioural states e and ne, respectively) and two columns (for behavioural states e and ne, respectively), the row related to alternative e isn't significant, because:

- if a generic household is evacuated in $\tau-1$, in $\tau$ the choice (e or ne) cannot be repeated; 
- if a generic household isn't evacuated in $\tau-1$, in $\tau$ the household can choose evacuating (e) or not (ne); therefore only the row related to behavioural state ne is significant and for this row a sequential dynamic discrete choice model could be proposed.

Table 3: General specification of transition frequency matrix for evacuation decision simulation.

\begin{tabular}{|c|c|c|c|c|}
\hline & $\tau$ & $\mathrm{e}$ & $\mathrm{ne}$ & \\
\hline$\tau-1$ & $\mathrm{e}$ & 0 & 0 & $\phi_{\mathrm{e}+}$ \\
\hline & $\mathrm{ne}$ & $\phi_{\mathrm{ne}, \mathrm{e}}$ & $\phi_{\mathrm{ne}, \mathrm{ne}}$ & $\phi_{\mathrm{ne}+}$ \\
\hline & & $\phi_{\mathrm{+e}}$ & $\phi_{\text {tne }}$ & \\
\hline
\end{tabular}

Table 4: Significant row of transition frequency matrix for evacuation decision simulation.

\begin{tabular}{|c|c|c|c|c|}
\hline & $\tau$ & e & ne & \\
\hline$\tau-1$ & ne & $\phi_{\text {ne, e }}$ & $\phi_{\text {ne,ne }}$ & \\
\hline
\end{tabular}

Formally, a sequential dynamic discrete choice model simulating evacuation decision is expressed as:

$$
\mathrm{P}^{\mathrm{n}, \tau}\left[\mathrm{e}^{\tau} / \mathrm{ne}^{\tau-1}\right]=\operatorname{prob}\left(\mathrm{U}^{\mathrm{n}, \tau}\left[\mathrm{e}^{\tau}\right]>\mathrm{U}^{\mathrm{n}, \tau}\left[\mathrm{ne} \mathrm{e}^{\tau}\right]\right) / \operatorname{prob}\left(\mathrm{U}^{\mathrm{n}, \tau-1}\left[\mathrm{ne}^{\tau-1}\right]>\mathrm{U}^{\mathrm{n}, \tau-1}\left[\mathrm{e}^{\tau-1}\right]\right) .
$$

Several hypotheses on random residual distribution could be considered. In relation to these hypotheses, the relation (5) can be specified.

The model could be developed for several user categories, as residents, nonresidents who systematically reach the area for work, non-residents who occasionally reach the area for shopping or other activities, and so on $[4,5]$. In relation to the specification of the systematic utility, several attributes could be introduced, related to socio - economic properties of the household and to characteristics of the considered dangerous event.

In some evacuation conditions RP data aren't available and, therefore, it's important to carried out evacuation trials, during which RP surveys may be viewed as physical checking SP data [22, 23]. Moreover, we have pointed out that main question of sequential analysis is to verify if specific transition frequencies from an antecedent to a consequent state differ from what would be expected if the two states were independent. Considering these aspects, we suggest a further approach to define sequential dynamic discrete choice model simulating evacuation conditions.

We suppose that a generic public decision maker plan a given number $(\mathrm{N})$ of evacuation trials, considering that a hypothetical dangerous event to come true. 
The public decision maker's aim is to verify if the household decision (evacuate or not) varies if this household has participate in the past to evacuation trials.

In this case, the choice set $\mathrm{C}$ includes, for each time $v$, the alternatives:

- $\quad$ evacuate in $v(\mathrm{e})$;

- $\quad$ non evacuate in $v$ (ne).

The transition frequency matrix is with two rows (for behavioural states e and ne, respectively) and two columns (for behavioural states e and ne, respectively): each row is significant, because the aims are to evaluate the evacuation frequency, in relation to a given number of evacuation trials and to the choice given in the previous time (table 5).

Table 5: Transition frequency matrix for evacuation decision simulation with data related to more evacuation trials.

\begin{tabular}{|c|c|c|c|c|}
\hline & $v$ & e & ne & \\
\hline$v-1$ & e & $\phi_{\mathrm{ee}}$ & $\phi_{\mathrm{e}, \mathrm{ne}}$ & $\phi_{\mathrm{e}+}$ \\
\hline & $\mathrm{ne}$ & $\phi_{\mathrm{ne}, \mathrm{e}}$ & $\phi_{\mathrm{ne}, \mathrm{ne}}$ & $\phi_{\mathrm{ne}+}$ \\
\hline & & $\phi_{\mathrm{ee}}$ & $\phi_{\mathrm{+ne}}$ & $\phi_{++}$ \\
\hline
\end{tabular}

Formally, a sequential dynamic discrete choice model simulating evacuation decision in this case is expressed as:

$$
\begin{gathered}
\mathrm{P}^{\mathrm{n}, v}\left[\mathrm{e}^{v} / \mathrm{ne}^{v-1}\right]=\operatorname{prob}\left(\mathrm{U}^{\mathrm{n}, v}\left[\mathrm{e}^{v}\right]>\mathrm{U}^{\mathrm{n}, v}\left[\mathrm{ne}^{v}\right]\right) / \operatorname{prob}\left(\mathrm{U}^{\mathrm{n}, v-1}\left[\mathrm{ne}^{v-1}\right]>\mathrm{U}^{\mathrm{n}, v-1}\left[\mathrm{e}^{v-1}\right]\right) \\
\mathrm{P}^{\mathrm{n}, v}\left[\mathrm{e}^{v} / \mathrm{e}^{v-1}\right]=\operatorname{prob}\left(\mathrm{U}^{\mathrm{n}, v}\left[\mathrm{e}^{v}\right]>\mathrm{U}^{\mathrm{n}, v}\left[\mathrm{ne}^{v}\right]\right) / \operatorname{prob}\left(\mathrm{U}^{\mathrm{n}, v-1}\left[\mathrm{e}^{v-1}\right]>\mathrm{U}^{\mathrm{n}, v-1}\left[\mathrm{ne}^{v-1}\right]\right) \\
\mathrm{P}^{\mathrm{n}, v}\left[\mathrm{ne}^{v} / \mathrm{e}^{v-1}\right]=\operatorname{prob}\left(\mathrm{U}^{\mathrm{n}, v}\left[\mathrm{ne}^{v}\right]>\mathrm{U}^{\mathrm{n}, v}\left[\mathrm{e}^{v}\right]\right) / \operatorname{prob}\left(\mathrm{U}^{\mathrm{n}, v-1}\left[\mathrm{e}^{v-1}\right]>\mathrm{U}^{\mathrm{n}, v-1}\left[\mathrm{ne}^{v-1}\right]\right) \\
\mathrm{P}^{\mathrm{n}, v}\left[\mathrm{ne}^{v} / \mathrm{ne}^{v-1}\right]=\operatorname{prob}\left(\mathrm{U}^{\mathrm{n}, v}\left[\mathrm{ne}^{v}\right]>\mathrm{U}^{\mathrm{n}, v}\left[\mathrm{e}^{v}\right]\right) / \operatorname{prob}\left(\mathrm{U}^{\mathrm{n}, v-1}\left[\mathrm{ne}^{v-1}\right]>\mathrm{U}^{\mathrm{n}, v-1}\left[\mathrm{e}^{v-1}\right]\right)
\end{gathered}
$$

Several hypothesis on random residual distribution could be considered. In relation to these hypothesis, the relation (6), (7), (8), (9) can be specified.

Also each of these models could be developed for several user categories and several attributes could be introduced in the systematic utility of each alternative.

The experimentation of proposed model in a real context is a work in progress and is characterized by the utilization of data obtained in the SICURO research project for general planning and demand analysis [4, 5, 23-27, 30, 39] and for supply and assignment [28, 29, 33-38].

\section{Sequential tests}

The reduction in uncertainty through knowledge of past events is the basic concept in sequential analysis. In order to assess the significance of this reduction in uncertainty, several tests can be applied $[19,20]$.

Among these: 
- the significance test allows the statistical significance of obtained sequences to be evaluated;

- the stationarity test allows us to evaluate whether the sequential structure of the data is the same regardless of where we begin in the sequence;

- the homogeneity test allows us to evaluate whether the sequential structure of the data is the same across subjects, or groups of subjects from which the sequences are obtained.

In the following we propose the specification of significance test to transition frequency matrix proposed in table 5 .

For the significance test, a particular model of event realization is supposed. The expected values that the model generates for a particular sequence are compared with those actually observed, by statistics:

with

$$
\text { Chi-squared } \left.\quad \mathrm{X}^{2}=\sum[\text { (obs-eps })^{2} / \text { eps }\right]
$$

- obs observed frequencies;

- eps expected frequencies, which we evaluate considering an equiprobable (or zero order) model, so called because it assumes that each kind of s-sequences occurs with equal probability [20];

- degrees of freedom equal to $(\mathrm{K}-1)^{2}$, with $\mathrm{K}$ number of alternatives.

If the test value is larger than that of reference, for a level $\alpha$ of significance (e.g. $\alpha=0.05$ ), the supposed model of event realization is rejected and the dependence between target and given event is verified. Similarly, tests can be applied for sequences if the same code in event sequences cannot be assigned and with $\operatorname{lag}>1$.

For table 5 the significance test is specified as in the following relations:

$$
\begin{gathered}
\mathrm{X}_{\mathrm{e}, \mathrm{e}}=\left[\phi_{\mathrm{e}, \mathrm{e}}-\mathrm{eps}(\mathrm{e}, \mathrm{e})\right]^{2} / \mathrm{eps}(\mathrm{e}, \mathrm{e}) \\
\mathrm{X}_{\mathrm{e}, \mathrm{ne}}=\left[\phi_{\mathrm{e}, \mathrm{ne}}-\mathrm{eps}(\mathrm{e}, \mathrm{ne})\right]^{2} / \mathrm{eps}(\mathrm{e}, \mathrm{ne}) \\
\mathrm{X}^{2}{ }_{\mathrm{ne}, \mathrm{e}}=\left[\phi_{\mathrm{ne}, \mathrm{e}}-\mathrm{eps}(\mathrm{ne}, \mathrm{e})\right]^{2} / \mathrm{eps}(\mathrm{ne}, \mathrm{e}) \\
\mathrm{X}_{\mathrm{ne}, \mathrm{ne}}^{2}=\left[\phi_{\mathrm{ne}, \mathrm{ne}}-\mathrm{eps}(\mathrm{ne}, \mathrm{ne})\right]^{2} / \mathrm{eps}(\text { ne,ne })
\end{gathered}
$$

where, considering the equiprobable model:

with

$$
\operatorname{eps}(e, e)=\operatorname{eps}(e, n e)=\operatorname{eps}(\text { ne, } n)=\operatorname{eps}(\text { ne,ne })=(1 / 4) \cdot \phi_{++}
$$

- 4 number of types of considered two-event sequences ((e,e), (e,ne), (ne,e), (ne,ne));

- $\phi_{++}$total number of observed two-event sequences.

\section{Conclusion}

In this paper the specification of sequential dynamic discrete choice models to simulate evacuation condition with sequential tests, able to ascertain whether current decisions are directly influenced by the most recent previous decisions, is proposed. Their experimentation using data obtained by a real experimentation in 
an urban area of the South Italy [4, 5, 23-39] is a work in progress. Good results have already been obtained from the experimentation of sequential dynamic discrete choice model simulating different user choices, as vehicle ownership $[16,18-20]$. The results of proposed sequential dynamic discrete choice model were compared in terms of rho-quadro bar value with some existing and fundamental dynamic models of literature. Good results for the proposed model are obtained.

A specific experiment, using a SP sample, is currently being developed; the objective is to obtain the first calibration for the model expressed by means of the equations (6)-(9)

Future objectives are to test sequential dynamic discrete choice models considering different hypotheses of covariance among alternatives related to the period t, using Probit and Mixed Multinomial Logit residuals, and test sequential dynamic discrete choice models to simulate different choice contexts, namely path choice.

\section{References}

[1] Domencich T.A. \& McFadden D., Urban travel demand: a behavioural analysis. American Elsevier, New York, 1975.

[2] Ben Akiva M. \& Lerman S., Discrete choice analysis: theory and application to travel demand. MIT Press, Cambridge, MA, 1985.

[3] Train K., Discrete choice methods with simulation. MIT Press, Cambridge, MA, 2003.

[4] Russo F. \& Chilà G., Domanda di trasporto in condizioni di emergenza. Modelli e metodi per la simulazione, applicazione ad un caso reale. FrancoAngeli, Milan, 2007.

[5] Russo F. \& Chilà G., Safety of users in road evacuation: demand models. Proc. of Urban Transport XIII, Urban Transport and the Environment in the 21st century, Brebbia C. A. (ed.), WIT Press, Southampton, pp. 773$782,2007$.

[6] Russo F. \& Vitetta A., Risk in anthropic environments: methodologies for risk evaluation and exposition reduction. In Environmental Health Risk III, Brebbia et al., WIT Press, Boston, 2005.

[7] Russo F. \& Vitetta A., Risk evaluation in a transportation system. International Journal of Sustainable Development and Planning, 1 (2), pp. 170-191, 2006.

[8] Russo F. \& Vitetta A., Safety of users in road evacuation: General methodology and main results. Proc. of Urban Transport XIII, Urban Transport and the Environment in the 21st century, Brebbia C. A. (ed.), WIT Press, Southampton, pp. 763-772, 2007.

[9] Wilmot C.G. \& Fu H., Static vs. Dynamic and Aggregate vs. Disaggregate: A Comparison Between Practice and Research in Hurricane Evacuation Travel Demand Modeling. Transp. Research Board 86th Annual Meeting, 2007. 
[10] Wilmot C.G., Fu H. \& H. Zhang, Modeling the Hurricane Evacuation Response Curve. Transportation Research Record: Journal of Transportation Research Record Board, No. 2022, Transportation Research Board of the National Academies, Washington, D.C., pp 94-102., 2007

[11] Nuzzolo A., Russo F. \& Cristalli U., A doubly dynamic schedule-based assignment mode for transit networks. Transportation Science, 2001.

[12] Cascetta E., Transportation Systems Engineering: Model and Application. Springer, Heidelberg, 2009.

[13] Hensher D.A. \& Le Plastrier V., Towards a dynamic discrete-choice model of household automobile fleet size and composition. Transportation Research, 19B, 481-495, 1985.

[14] Mohammadian A. \& Miller E., Dynamic modeling of household automobile transactions. Transportation Research Record, 1831, 98-105, 2003.

[15] Russo F. \& Chilà G., Sequential models for mobility decisions: experimentation for vehicle holding choices. Proceedings of the European Transport Conference 2007, Leeuwenhorst, The Netherlands, 17-19 October 2007.

[16] Russo F. \& Chilà G., Probit Sequential Model for User's Choices. Proceedings of European Transport Conference 2008, Noordwiikerhout (NL), 2008.

[17] Train K. \& Winston C., Vehicle choice behavior and the declining market share of U.S. Automakers. International Economic Review, 48(4), 14691496, 2007.

[18] Gottman J.M. \& Roy K.A., Sequential Analysis. Cambridge University Press, New York, 1990.

[19] Bakeman R. \& Gottman J.M., Observing interaction. An introduction to sequential analysis. Cambridge University Press, New York, 1997.

[20] Chilà G., Sequential methods for user choices: tests and properties applied to a panel database. Proc. of Urban Transport XIV, Urban Transport and the Environment in the 21 st century, Brebbia C. A. (ed.), WIT Press, Southampton, 2008.

[21] Russo F. \& Chilà G., Dynamic approaches to demand model in evacuation conditions. Proc. of Urban Transport XVI, Urban Transport and the Environment in the 21 st century, Brebbia C. A. (ed.), WIT Press, Southampton, 2010.

[22] Ortuzar J. de D. \& Willumsen L.G., Modelling Transport. John Wiley \& Sons Ltd, Chichester, 2006.

[23] Russo F. \& Chilà G., Safety of users in road evacuation: RP vs. SP surveys in demand analysis. Proc. of Urban Transport XIV, Urban Transport and the Environment in the 21st century, Brebbia C. A. (ed.), WIT Press, Southampton, pp. 703-713, 2008.

[24] Russo F. \& Rindone C., Safety of users in road evacuation: planning internal processes and guidelines. Proc. of Urban Transport XIII, Urban Transport and the Environment in the 21st century, Brebbia C. A. (ed.), WIT Press, Southampton, pp. 825-834, 2007. 
[25] Russo F. \& Rindone C., Safety of users in road evacuation: the logical framework approach in evacuation planning. Proc. of Urban Transport $X I V$, Urban Transport and the Environment in the 21st century, Brebbia C. A. (ed.), WIT Press, Southampton, pp. 751-760, 2008.

[26] Russo F. \& Rindone C., Safety of users in road evacuation: Modelling and DSS for LFA in the planning process. Proc. of Sustainable Development and Planning IV, vol.1, Brebbia C. A. (ed.), WIT Press, Southampton, pp. 453-464, 2009.

[27] Russo F. \& Chilà G., Safety of users in road evacuation: Modelling and DSS for demand. Proc. of Sustainable Development and Planning IV, vol.1, Brebbia C. A. (ed.), WIT Press, Southampton, pp. 465-474, 2009.

[28] Vitetta A., Quattrone A. \& Polimeni A., Safety of users in road evacuation: design of path choice models for emergency vehicles. Proc. of Urban Transport XIII, Urban Transport and the Environment in the 21st century, Brebbia C. A. (ed.), WIT Press, Southampton, pp. 803-812, 2007.

[29] Vitetta A., Musolino G. \& Marcianò F.A., Safety of users in road evacuation: Supply and demand-supply interaction models for users. Proc. of Urban Transport XIII, Urban Transport and the Environment in the 21st century, Brebbia C. A. (ed.), WIT Press, Southampton, pp. 783-792, 2007.

[30] Russo F. \& Rindone C., Data Development Analysis (DEA) for evacuation planning. Proc. of Seventh International Conference on Computer Simulation in Risk Analysis and Hazard Mitigation, Brebbia C. A. (ed.), WIT Press, Southampton, 2010.

[31] Marcianò F.A., Musolino G. \& Vitetta A., Signal setting design on a road network: application of a system of models in evacuation conditions. Proc. of Seventh International Conference on Computer Simulation in Risk Analysis and Hazard Mitigation, Brebbia C. A. (ed.), WIT Press, Southampton, 2010.

[32] Polimeni A., Quattrone A. \& Vitetta A., An approach to design vehicle routes in evacuation conditions. Proc. of Seventh International Conference on Computer Simulation in Risk Analysis and Hazard Mitigation, Brebbia C. A. (ed.), WIT Press, Southampton, 2010.

[33] Vitetta A., Musolino G. \& Marcianò F. A., Safety of users in road evacuation: calibration of cost functions and simulation. Proc. of Urban Transport XIV, Urban Transport and the Environment in the 21st century, Brebbia C. A. (ed.), WIT Press, Southampton, pp. 715-725, 2008.

[34] Vitetta A., Musolino G. \& Marcianò F.A., Safety of users in road evacuation: Modelling and DSS for transport supply and supply-demand interaction. Proc. of Sustainable Development and Planning IV, vol.1, Brebbia C. A. (ed.), WIT Press, Southampton, pp. 475-484, 2009.

[35] Marcianò F. A., Musolino G. \&Vitetta A., A system of models for signal setting design of a signalized road network in evacuation conditions. Proc. of Urban Transport XVI, Urban Transport and the Environment in the 21st century, Brebbia C. A. (ed.), WIT Press, Southampton, pp. 313-323, 2010.

[36] Vitetta A., Quattrone A. \& Polimeni A., Safety of users in road evacuation: algorithms for path design of emergency vehicles, Proc. of Urban 
Transport XIV, Urban Transport and the Environment in the 21st century, Brebbia C. A. (ed.), WIT Press, Southampton, pp. 727-737, 2008.

[37] Vitetta A., Quattrone A. \& Polimeni A., Safety of users in road evacuation: Modelling and DSS for paths design of emergency vehicles. Proc. of Sustainable Development and Planning IV, vol.1, Brebbia C. A. (ed.), WIT Press, Southampton, pp. 485-495, 2009.

[38] Polimeni A., Quattrone A. \& Vitetta A., A tool for tracing emergency vehicles during evacuation, Proc. of Urban Transport XVI, Urban Transport and the Environment in the 21st century, Brebbia C. A. (ed.), WIT Press, Southampton, pp. 325-333, 2010.

[39] Russo F. \& Rindone C., Evaluation methods for evacuation planning. Proc. of Urban Transport XVI, Urban Transport and the Environment in the 21st century, Brebbia C. A. (ed.), WIT Press, Southampton, pp. 335-343, 2010. 